\title{
Interpreting genetic risks
}

\author{
J Pearn, MD, PhD, DSc, FRACP, FRCP (Lond), FRCP (Edin), FRCPS (Glas), FLS \\ Emeritus Professor of Paediatrics and Genetics, Lady Cilento Children's Hospital, South Brisbane, Australia, and Sometime Surgeon General, \\ Australian Defence Force, Brisbane, Australia
}

Corresponding author: J Pearn (j.pearn@uq.edu.au)

Prof. Peter Beighton has given a professional lifetime to helping patients and their families who have been afflicted by inherited disease. His clinical skills have brought certainty, confidence and support to those confronted with some of the most difficult decisions in life's progress. Prof. Beighton's research has led to the discovery of new syndromes and the elucidation of accurate genetic risks in many diseases. This in turn has empowered patients and their families to make informed decisions and has provided doctors with the scientific knowledge to help patients. On the occasion of this festschrift, I join with so many members of Peter's international professional family to pay tribute to his leadership and service - not only in medical genetics - but also in the broadest domains of healthcare.

S Afr Med J 2016;106(6 Suppl 1):S87-S89. DOI:10.7196/SAMJ.2016.v106i6.11004

Emeritus Professor John Pearn is a paediatrician, geneticist and former neurologist, based in Brisbane, Australia. He was Prof. Beighton's guest as Visiting Professor of Medical Genetics at the University of Cape Town in 1982. John Pearn and Peter Beighton collaborated in research and published on inherited musculo-skeletal diseases. Both Peter Beighton and John Pearn served in the Parachute Regiment of the British Airborne Forces. Later (1998-2000), Major General John Pearn served as Surgeon General in the Australian Defence Force.

\section{Doctors, patients and risk}

Within the domain of best-practice medicine, the definition of a specific diagnosis is the first step in every clinical interaction. Therein is a gradation of specificity. Syndromic diagnosis, important as it is, is the most general. Rather than syndromes, doctors aim to diagnose specific disease. Progressively, research leads to genetic specificity and biochemical identity and ultimately to molecular definition of the fundamental disease or congenital abnormality that leads a patient to seek medical help.

The pathway to achieve such diagnostic specificity is a five-link chain, of which the generation of a differential diagnosis is the pivotal link. That chain comprises: taking a history, examining the patient, generating a differential diagnostic list, performing tests and investigations and, ultimately, making a definitive diagnosis. ${ }^{[1]}$

Genetic diseases comprise a significant component of clinical practice. The occurrence and even the severity of many non-genetic conditions (injuries are an extreme example) are also influenced by a person's genetic makeup. For every person diagnosed with a genetic disease in medical terms, the proband or index patient, there are potentially scores of first-, second- and third-degree relatives who may be enmeshed in consequences of a relative's genetic diagnosis. Such also seek counsel about genetic risks of recurrence. From the patient's point of view, it matters little whether or not a simple phenotypic diagnosis is made, or whether a disease can be defined in molecular terms. From the patient's point of view, the two most fundamental questions that are sought are:

1. What is the risk of recurrence?

2. If another child or family member develops the disease in question, what is the likely severity?

The generation and transmission of such genetic risks comprise the end-point of the diagnostic chain. How patients interpret such risks has been the subject of much research. ${ }^{[3-6]}$ This theme is not specific to genetically determined disease and is universal in all aspects of healthcare. It ranges from those contemplating the risks of surgery to how one balances costs against the threat of preventable disease. It is of no less importance to those who volunteer as subjects for medical research. ${ }^{[7]}$

\section{Risks and their interpretation}

Risks can be interpreted in many ways. Absolute risk is expressed in mathematical terms, and if the research to quantify risk is of high integrity, the mathematical risk is absolute. Risk is the threat or potential for harm, misadventure or unfortunate outcome with diverse consequences. Such potential is expressed in terms of probability. Probability is a complex psychological construct. It refers to the percentage of a featured outcome within a group as the end-point summary of repeated sequences or trials. As individuals, we transfer this concept of group probability to ourselves, and we impart the concept of probability to personal risk. Harm or the deleterious result of a single or specific 'gamble' is the outcome of realised risk.

Absolute risk is an inviolate mathematical truth. As individuals, we use this basic mathematical truth to construct a personal concept of risk, in any one of many different forms. Collectively, these comprise the subjective interpretation of risk. ${ }^{[3]}$ Such internalisation of risk determines the way in which individuals respond to uncertain situations. It matters little whether that risk is imposed on an individual by external circumstances or whether an individual actively seeks out to partake in an action or endeavour with uncertain outcome.

Some imagine the concept of risk as a linear scale of probability and imagine themselves as occupying one point on that scale. My own research showed that such a scale is not a ratio or interval scale, but one with distortions along its extent. ${ }^{[5]}$ Some use the concept of relative risk, a second order comparison, by introducing an unrelated scale of risk and placing the featured risk not in absolute terms, but as one relative to the unrelated risk. Others, perhaps 10 per cent of the population, regard risk as a binary concept - 'either one will get the feature outcome or not, irrespective of the absolute mathematical risk involved? ${ }^{[5]}$

The subjective interpretation of risk is a universal phenomenon. We act according to its dictates, rather than to any concept of 
absolute risk. It has long been known that professional statisticians and mathematicians, if clandestinely observed at a roulette table, do not gamble according to the mathematical risks with which they are confronted, but according to the imposts of subjective risk..$^{[8-10]}$ At roulette, such professional statisticians are more likely (greater than $50 \%$ ) to gamble on a 'red' after a run of 10 or so 'blacks', even though the mathematical probability remains 1 in 2 , or $50 \%$. In absolute terms, 'the die has no memory', but in the pragmatic world of obligate decision-making, we are influenced as if it had.

Helping patients to interpret risks that confront them is one facet of the art, as opposed to the science, not just of medicine but of all healthcare.

\section{Absolute risk \\ The calculation of a patient's risk of genetic recurrence is the domain of the attending clinician, with the help of geneticists and pathologists. Such include the specialty professions of cytogenetics, biochemistry and molecular biology. If one is calculating risks for a patient prior to the conception of a new infant, a range of techniques are available, including carrier detection studies. Such may also include issues of mosaicism, lyonisation and Bayesian statistics. With the advent of molecular biology and genome sequencing, much of the earlier (i.e. pre-1990) problems of complex biochemical analyses have been bypassed. If index patients have died, or if diagnostic samples are not available (either due to untraceability or refusal to supply specimens) the traditional use of Bayesian statistics may still have to be employed. Whatever are the difficulties, an absolute risk (or range of risk) can almost always be calculated. \\ This calculation of the absolute risk is the first step and forms the basis of genetic counselling. One role of the medical geneticist or genetic counsellor is to discuss the absolute risk, such that the patient's subjective risk has pragmatic relevance to those who will bear its ultimate consequences if realised, or who will enjoy the outcome if not. The style of such counselling varies across the spectrum from relative non-directedness, through shared decision-making, to that of more directed recommendations. ${ }^{[6]}$}

\section{Subjective interpretation of risk}

Decision-making is important in everyday life and almost always involves the interpretation and balancing of risks. Every decision in clinical medicine on the part (ultimately, independently) of both doctors and the patients whom they treat, depends on the subjective interpretation of what can be assessed or presented as objective or absolute risk.

Emotions, comprising both subjective and physiological components, modify the way in which risk is subjectively interpreted. ${ }^{[1]}$ Neural processing during risk analysis and risk-taking is associated with increased neuroimaging signals in the insula and anterior cingulate gyrus. ${ }^{[12]}$ Different parts of the pre-frontal cortex are associated with cognitive focusing on objective risk. Different parts of the brain 'light up' under magnetic resonance imaging studies when risk-averse individuals are compared with risk-seeking individuals, at least in research undertaken to study risk behaviour in the context of financial decisions. ${ }^{[13]}$

It has long been known that there are at least six major determinants that influence the way in which objective risk is subjectively interpreted. ${ }^{[3]}$ These include (i) the way in which risk figures are presented; (ii) the anticipation of the risk odds prior to receiving information on objective risk; (iii) the nature of the outcome if the risk eventuates, potentially causing hurt or harm; (iv) individual personality; $(v)$ prior runs of good or bad luck; and (vi) time factors which determine whether a gamble has to be accepted with immediacy or can be deferred.

Personality factors are of dominant importance in the way in which objective or absolute risk is interpreted and in the way decisionmaking follows. ${ }^{[14]}$ There exists a spectrum of such personalities, ranging from those who are higher risk-acceptors (sometimes courageous gamblers!) to those who are extremely risk-averse. A simple example was proposed by Dr Christopoulos and colleagues from Cambridge University: Consider somebody selling you a lottery ticket offering [a prize of] $£ 40$ or $£ 60$, depending on the flip of a coin. You decide to pay up to $£ 50$ to buy this ticket. Conversely, your friend might consider this ticket as risky and pay a maximum of $£ 45$. Although both of you face exactly the same average payoff, your reactions are different and vary between risk neutrality (you) and risk avoidance (your friend). Such decisions involving risky options characterise a wide spectrum of human and animal behaviour. ${ }^{[15]}$

The pessimistic person ('just my bad luck!') tends to increase his or her subjective view of risk. The optimist ('it can't happen to me') believes that although they may be subject to what some would regard as a general risk, somehow their real personal risk is much less.

\section{Runs of good and bad luck}

If two successive children have been born affected by a polygenetically determined condition such as a neural tube defect or a cleft lip, the objective risks of recurrence for the next pregnancy are in the order of 1 in 8 to 1 in 10. My experience is that in many such cases, the 'run' of an unfortunate outcome may influence the parents subjectively to interpret their recurrence risk as more threatening than they otherwise would. Other examples have been recorded where a run of sequential pregnancies has each resulted in the birth of an infant with fatal infantile spinal muscular atrophy. ${ }^{[2]}$ In this instance, although the recurrence risks for other pregnancies are fixed (autosomal recurrence risks of 1 in 4), parents distressed by this experience may not embark on another pregnancy, although the risk of a normal child is $75 \%$. It has long been known that the psychological influence of a run of good or bad luck (run dependency) is strong. ${ }^{[8]}$

There exist two common erroneous beliefs about randomness in any wager with a binary outcome. These are the 'gambler's fallacy' and the 'hot hand fallacy'. There exists a comprehensive corpus of research on each of these misconceptions, primarily in the psychological research literature relating to wagering practices. Nevertheless, I believe that such influences probably relate to all forms of risk-taking.

Those influenced by the gambler's fallacy act as if long outcome runs (black, black, black ... black) modify the probability of a subsequent alternative (red) outcome. This is a powerful influence, especially (in the gambling context) in loss-chasing. ${ }^{\left[{ }^{[0]}\right.}$

The alternative influence, the 'hot hand fallacy', modifies decisionmaking under binary randomness, and influences subjects to keep to a supposed winning streak. ${ }^{[10]}$

In the domain of genetic counselling, if parents decide to embark on a pregnancy in the face of genetic risk, the outcome is thought by a significant proportion of individuals to be a binary one - either good (the birth of a normal infant) or unfavourable (if the index disease recurs). In the genetic context, it has long been known that sex differences in attitude to risk are well-known. ${ }^{[3]}$ Males who are motivationally characterised risk-takers are generally dissatisfied when they adopt a conservative (risk-averse) strategy. ${ }^{[16]}$ 


\section{Pretest counselling}

The results of any medical test can modify one's life. Early (sometimes, pre-symptomatic) testing can detect disease states and effect cure. In contrast, test results in otherwise healthy individuals can result in the deleterious modification of life to no avail if a disease is untreatable. Presymptomatic testing for such conditions as Huntington's chorea and Duchenne muscular dystrophy are extreme examples.

Another topical example is $B R C A 1$ or $B R C A 2$ genetic testing for women with a family history of breast cancer. The way in which women interpret the results of such genetic threat is highly variable. The majority (71\%) of women who currently undergo $B R C A 1$ and $B R C A 2$ testing in the USA receive results that are either ambiguous or uninformatively negative. ${ }^{[17]}$ The minority who receive straightforward positive or negative test results usually interpret these correctly. Nevertheless, between 2 and $8 \%$ of women misinterpret even straightforward results. ${ }^{[18]}$ Those (the majority) who receive uninformative or ambiguous results were even less likely to interpret the significance of the results. Such interpretation requires considerable skills in numeracy - on behalf of both patients and counsellors. ${ }^{[18]}$

One implication of the extensive research on risk interpretation in the medical domain is that pre-test counselling is essential. This issue is topical, as do-it-yourself genetic testing is currently increasing; and can result in distress (not only in index patients but in extended members of the kindred) which is unfortunate, unnecessary and preventable.

It may seem obvious, but it is important to reinforce the fact that a risk of disease or disability is not the disease itself. This has been emphasised particularly in the context of cardiovascular risk calculators, where some 'doctors try to manage risks as if they were the disease itself and, as a result, patients are subjected not only to undergo worry but also to the harmful side-effects of preventive medication and testing.[?]

\section{Relative risks}

In addition to the constraints and influences above, the process of decision-making under risks includes two further themes. These are the concept of relative risk and a construct known in medical terms as the 'number needed to treat. ${ }^{\text {[19] }}$

In the context of relative risk, consider a couple in whose family cystic fibrosis has occurred. Prior to carrier detection testing, the risk of occurrence might be 1 in 4,1 in 100 or the random population risk - in Western societies, 1 in 2 500. Depending on whether a patient thinks in decimal terms or percentages, a 1 in 2 risk can be expressed as $50 \%, 0.5,1$ in 2 or visually as a pie chart with half the circle shaded. ${ }^{[3,4]}$

The risk to a woman having a baby who has a niece with cystic fibrosis is in the order of 1 in 200; but the chance of any couple having a baby with a significant physical or mental abnormality is 1 in 50 (2\%). Such couples, who might have interpreted the 1 in 200 as a high risk, subjectively see this as less threatening when the more general (but higher) absolute risk is seen in perspective. Relative risk is often referred to jokingly to self-mitigate a specific risk. One sometimes hears the phrase 'well, the chance of being run down by a car is higher!'

The concept of relative risk is inescapable whenever one is prescribed medication. The risk of side-effects needs be balanced against the untreated primary disease. If one is speaking of preventive drugs or preventive treatment (e.g. statins to reduce the risk of heart attack), it is important that individuals should discuss with their doctor if the reduction in the absolute risk outweighs the risky sideeffects and costs of treatment. This in turn leads to the concept of 'numbers needed to treat'. The use of statins is again a case in point. Using the cardiovascular risk calculator of the American Heart Association, one notes that for every 100 subjects treated with statins to prevent heart attacks: (i) only four are spared by the use of statins; (ii) 85 are spared heart attacks even if they had not taken statins; and (iii) 11 are stricken by a heart attack in spite of having taken statins; and (iv) 5 have chronic muscle pain. ${ }^{[7]}$

One interpretation of the risks involved can take the path of deciding which of the above sub-groups affords the most 'utility' for the patient, as an individual.

\section{Conclusion}

Decision-making is of fundamental importance in everyday life, and particularly in the domains of personal and family healthcare. A significant proportion of the greater than six million articles published annually present data concerning risk and risk reduction. ${ }^{[20]}$ The detailed understanding and a focus of the way in which medical decisions are made can lead to a distorted perspective of the end-point of such personal decisions. That end-point is an individual, often perplexed and sometimes fearful, divided between the goals of having healthy children or optimal health on the one hand, and the concern of life-modifying sequelae on the other. There is a genetic counsellor and decision-making advisor in every healthcare professional. Their sensitivity and skills occupy a place of special trust and great privilege in the lives of those who seek their counsel.

\section{References}

1. Pearn J. Differentiating diseases: The centrum of differential diagnosis in the evolution of Oslerian medicine. Fetal Pediatr Pathol 2011;30(1):1-15

2. Roberts JA. Genetic prognosis. Br Med J 1962;1(5278):587-592

3. Pearn JH. Patients' subjective interpretation of risks offered in genetic counselling. J Med Genet 1973;102:129-134

4. Pearn JH. The subjective interpretation of medical risks. Medikon 1977;5(5):5-8.

5. Pearn J, Axter B. Attitudes to genetic risks. A comparative study of parents from a genetic counselling clinic and a group of graduating doctors. Aust Paediatr J 1977;13(3):231-232.

6. Elwyn G, Gray J, Clarke A. Shared decision making and non-directiveness in genetic counselling. I Med Genet 2000;37(2):135-138.

Wheelwright J. Risky medicine. Aeon. http://aeon.co/magazine/health/is-preventive-medicine-itsWheelwright J. Risky medicine. Aeon. http:/
own-health-risk (accessed 7 September 2015).

Beach LR, Swensson RG. Instructions about randomness and run dependency in two-choice learning J Exp Psychol 1967;75(2):279-282.

J Exp Psychol 1967;75(2):279-282.
Studer B, Limbrick-Oldfield EH, Clark L. 'Put your money where your mouth is!': Effects of streaks on confidence and betting in a binary choice task. J Behav Decis Mak 2015;28(3):239-249.

10. Oskarsson AT, van Boven L, McClelland GH, Hastie R. What's next? Judging sequences of binary events. Psychol Bull 2009;135(2):262-285. DOI:10.1037/a0014821

1. Lang PJ, Davis M. Emotion, motivation and the brain: Reflex foundations in animal and human research. Prog Brain Res 2006;156:3-29.

12. Ohira $\mathrm{H}$, Ichikawa $\mathrm{N}$, Nomura $\mathrm{M}$, et al. Brain and autonomic association accompanying stochastic decision-making. Neuroimage 2010;49(1):1024-1037. DOI:10.1016/j.neuroimage.2009.07.060

13. Holper $\mathrm{L}$, Wolf M. Tobler PN. Comparison of functional near-infrared spectroscopy and electroderm activity in assessing objective versus subjective risk during risky financial decisions. Neuroimage activity in assessing objective versus subjective risk during.
2014;84:833-842. DOI:10.1016/.neuroimage.2013.09.047

14. Slovic P, Finucane ML, Peter E, MacGregor DG. Risk as analysis and risk as feelings: Some thoughts about affect reason, risk and rationality. Risk Anal 2004:24(2):311-322.

15. Christopoulos GI, Tobler PN, Bossaerts P, Dolan RJ, Schultz W. Neural correlates of value, risk, and risk aversion contributing to decision making under risk. J Neurosci 2009;29(40):12574-12583. DOI:10.1523/JNEUROSCI.2614-09.2009

16. Alker HA. Rationality and achievement: A comparison of the Atkinson-McClelland and KoganWallach formulations. J Personality 1969;37(2):207-221.

17. Ardern-Jones A, Kenen R, Lynch E, et al. Is no news good news? Inconclusive genetic test results in BRCA1 and BRCA2 from patients and professionals' perspectives. Hered Cancer Clin Pract 2010;8(1):1-8. DOI:10.1186/1897-4287-8-1

18. Hanoch Y, Miron-Shatz T, Rolison JJ, Ozanne E. Understanding of BRCA1/2 genetic tests results the importance of objective and subjective numeracy. Psychooncology 2014;23(10):1142-1148. DOI:10.1002/pon.3537

19. Barratt A, Wyer PC, Hatala R, et al. Tips for learners of evidence-based medicine: 1. Relatve risk reduction, absolute risk reduction and number needed to treat. CMAJ 2004;171(4):353-358.

20. Irvine EJ. Measurement and expression of risk: Optimizing decision strategies. Am J Med 2004;117 (Suppl 5A):2S-7S 